\title{
Finite Element Analysis of a Sandwich Pipe Joint
}

Ikechukwu Onyegiri, Maria Kashtalyan*

Centre for Micro- and Nanomechanics (CEMINACS), School of Engineering, University of Aberdeen, Fraser Noble Building, Aberdeen AB24 3UE, Scotland UK

*Corresponding author: m.kashtalyan@abdn.ac.uk

\begin{abstract}
Sandwich pipes in which the core material performs both thermal insulation and structural function are viewed as a lightweight alternative to conventional pipe-in-pipe systems in which insulation material carries no loading. Developing a suitable method that permits the joining of sandwich pipes in an efficient manner is essential for their successful application. In this paper, the mechanical response of a swaged field joint between sandwich pipes subjected to bending is investigated using a series of finite element models. In order to gain a thorough understanding of the response of the joint components to installation based loadings, parametric studies are carried out to establish the effect of the inner pipe thickness, cutback length, and stiffness of the field joint filler on the strain concentration at the joint, with particular focus on the swaged weld region and the girth weld region. The influence of interface adhesion properties and weld metal yield strength on the variation of strain intensity is also evaluated. Numerical studies show that increasing filler stiffness and maintaining a cutback length less than 2.5 times the radius of the inner pipe could produce lower strain intensity at the two regions of interest.
\end{abstract}

\section{Keywords}

Sandwich pipe; field joint; strain concentration; finite element modelling 


\section{Introduction}

As oil and gas production moves to deep- and ultra-deep waters, new pipeline configurations are required to meet simultaneous demands for thermal insulation and structural integrity to ensure safe and reliable transportation of hydrocarbons. Over the past two decades pipe-in-pipe systems have been developed for fields with flow assurance challenges (Bai and Bai, 2014; Sriskandarajah et al, 2016). However, with increasing water depths and associated increasing demands on structural performance, the pipe wall thickness in pipe-in-pipe systems will have to increase, with pipe-in-pipe systems becoming exceedingly heavy and uneconomical (Bruschi et al, 2015), and lightweight alternatives will need to be sought.

In the pipe-in-pipe concept, the annular space between the inner pipe and outer pipe is not used to its full structural potential because the insulation material does not perform any structural function. In contrast, a sandwich pipe combines thermal insulation and structural performance in its design and attempts to realise the full structural potential of the annular space.

A sandwich pipe typically consists of two thin-walled pipes - an inner pipe and an outer pipe - and a core layer that completely fills the annular space between the pipes and is bonded to them. The concept of sandwich pipelines has been studied for over a decade now. Estefen, Netto and Pasqualino (2005) performed small-scale tests and strength analysis of sandwich pipes under combined external pressure and longitudinal bending. They showed that sandwich pipe systems with either cement or polypropylene cores are feasible options for ultra deepwater applications. Buckling capacity of sandwich pipes with various structural configurations and core materials, subject to external hydrostatic pressure was studied by Arjomandi and Taheri (2010) using an analytical approach. Arjomandi and Taheri (2011a-c) also performed extensive finite element modelling of sandwich pipes to analyse different bonding scenarios at the interfaces between the core layer and the pipe layers and examined the effect of material and geometrical nonlinearities on the pipe buckling and post-buckling behaviour. Behaviour of sandwich pipe systems under pure bending was examined by Arjomandi and Taheri (2012) while reeling effects was studied by (Paz et al., 2015). Collapse behaviour of sandwich pipes with strain hardening cementitious composite reinforced with polyvinylalcohol (PVA) fibers as a core material was investigated experimentally and numerically by (An et al., 2014). A parametric study examined the effects of ovality, thickness and outer/inner radius ratio on the collapse pressure of these sandwich pipes. Post-buckling responses and pressure capacity of sandwich pipes with the solid polypropylene core was investigated by (He et al., 2015) using finite element modelling. 
Developing a suitable method that permits the joining of sandwich pipes in an efficient manner preserving the integrity of the insulation and the mechanical properties is essential for successful application of sandwich pipes, however joining of sandwich pipes has received considerably less attention in the literature.

Offshore pipeline joints (referred to as field joints) that link two adjoining pipe sections represent a critical design area during installation and operation analysis. The design of a joint usually follows set guidance criteria established wholly by the loadings the field joint would undergo from fabrication and throughout operation (Thielhelm, 1968). For pipe-in-pipe systems, several joint configurations were proposed (Hausner and Dixon, 2004). In sliding pipe-in-pipe systems, field joints require welding of both the inner and outer pipes. Fixed pipe-in-pipe systems utilise either swaged connector, forged bulkheads or forged tulips that are welded to both the inner and the outer pipe (Hooper et al., 2004). In a swaged joint configuration developed by InTerPipe, the ends of the outer pipe are swaged down and welded unto the outer surface of the inner pipe at the ends of pipe segments; this is carried out onshore. Segments of the pipe are transported to the offshore lay vessel where the ends of the inner pipes are joined together by a girth weld. To make a complete connection, a sleeve is placed over the girth weld and the swaged section of the pipe, and fast-curing resin is injected into the cavity. This joining method is considerably faster than welding both inner and outer pipes and is suitable for J-lay and S-lay methods (Janton, 2006). More recently, a reelable bulkhead pipe-in-pipe technology (Boi et al., 2012) and a swaged joint with flush welded half shells for reel lay (Jones et al., 2013) have been developed. Design aspects of pipe-in-pipe systems for high pressure/high temperature (HP/HT) applications are discussed by Sriskandarajah et al (2016).

The swaged joint configuration with flush half shells arguably represents the most effective way for providing continuity of bending stiffness (Hooper et al., 2004). Bending is one of the primary loading conditions experienced by pipeline during installation and in-service. Bending loads are inevitable when laying offshore pipelines and the response of field joints to high levels of curvature requires comprehensive study of all joint components (Dickson et al., 2003).

Sandwich pipe joints are expected to behave in a manner similar to pipe-in-pipe joints, with the main difference being the effect of the extra stiffness added by the core material. This makes the swage and half shells weld even more critical due to the enhanced transfer of bending loads across the field joint region. In sandwich pipes, bending will lead to stress and strain concentrations at the field joint similar to those experienced by field joints in pipe-in-pipes, however the effect of the structural core on the mechanical response of the field joint has not been quantified yet. 
The aim of this study is to analyse, by means of finite element method, performance of a swaged joint between sandwich pipes and establish the effect of both geometrical and mechanical properties of field joint components on the strain concentration at the joint.

\section{Design Considerations}

Strain concentration at the field joint is a result of variation in bending stiffness along the pipe (Roberts et al., 2009). On the application of a bending moment, longitudinal strains in tension and compression are experienced and can be analysed starting from the girth weld connecting two adjacent inner pipe ends to some distance along the inner pipe where the swaged weld toe is encountered. The magnitude of strain especially in the girth weld is dependent on weld shape, wall thickness variation, pipe ovality and weld metal mismatch (Dixon et al., 2003).

Strain concentration is an important design input for field joint design. The severity of strain concentration in the field joint area is represented by the strain intensity factor (SIF), which is sometimes also called strain concentration factor. It is simply defined as

$S I F=\frac{\varepsilon_{\max _{-} F J}}{\varepsilon_{g}}$

where $\varepsilon_{\max _{-} F J}$ is the maximum longitudinal strain at the field joint and $\varepsilon_{g}$ is the global bending strain calculated by the Euler beam theory:

$\varepsilon_{g}=\frac{k D}{2}$

where $k$ is the applied curvature and $D$ is the outer diameter of the pipe. The curvature can be written in terms of pipe length $L$ and the rotational displacement of the pipe $\theta$ in radians as

$k=\frac{\theta}{L}$

Comparative models employed to verify the accuracy of Eq. (2) confirmed the plausibility of using the Euler beam theory to calculate global strain for materials undergoing plastic deformation. The results revealed that up until the point of yield, Eq. (2) captured the global strain accurately. Post yield results showed an undervaluing of the global strain results by Eq. (2). A correction polynomial function was thus used to accurately define the global bending strain after yield $\left(\varepsilon_{g}^{\text {corr }}\right)$ by post yield data obtained by Eq. (2) and results obtained from the comparative FEA model: 
$\varepsilon_{g}^{\text {corr }}=159.57 \varepsilon_{g}^{3}-2.4444 \varepsilon_{g}^{2}+1.0493 \varepsilon_{g}-0.00009$

The yield curvature $k_{y}$ at which the inner pipe outer fibre begins to yield is defined by the empirical expression:

$k_{y}=\frac{\sigma_{y}}{E \cdot r_{i}}$

Using the formulation above, a radius of curvature $\left(R_{\text {curv }}\right)$ at yield of $50.6 \mathrm{~m}$ is calculated; showing close alignment with the $R_{\text {curv }}$ at yield of $49.8 \mathrm{~m}$ obtained from a comparative FEA model of the inner pipe undergoing pure bending.

The reference value for SIF as quoted by DNV (DNV, 2013; Bai and Bai, 2014) is 1.2 for conceptual design in the absence of detailed engineering, a value that analysis by Nourpanah and Taheri (2012) showed only to be precise for pipelines with light insulation and exposed to relatively low bending strain. For curvatures representing reeling (plastic deformation), SIF values would be larger as represented in work done by Crome (1999) who studied the reeling of pipelines with thick insulation. The same conclusion was reached by Sriskandarajah et al. (2003) who showed that due to non-uniformity of material properties and adjacent geometries, the effect of strain concentrations will arise which will yield higher strain levels than the normal design strains due to the reel drum radius.

The geometry of the swaged joint is shown in Fig. 1, together with several areas of interest. First is the inner pipe region between the girth weld and the swaged weld (cutback length), which can be analysed as a single pipe bordered at two ends by greater stiffness cross sections. The next is the fusion area between the inner pipe and the swaged weld which is a full penetration weld. Another region of interest would be the inner pipe length just after the swaged weld. In the outer region, the critical zones include: the fillet interface (extrados) with the buttered weld and the half shell region. The structural integrity of the welds is also of paramount importance as it to a large extent controls the mechanical response of the field joint but is outside the scope of this paper. 


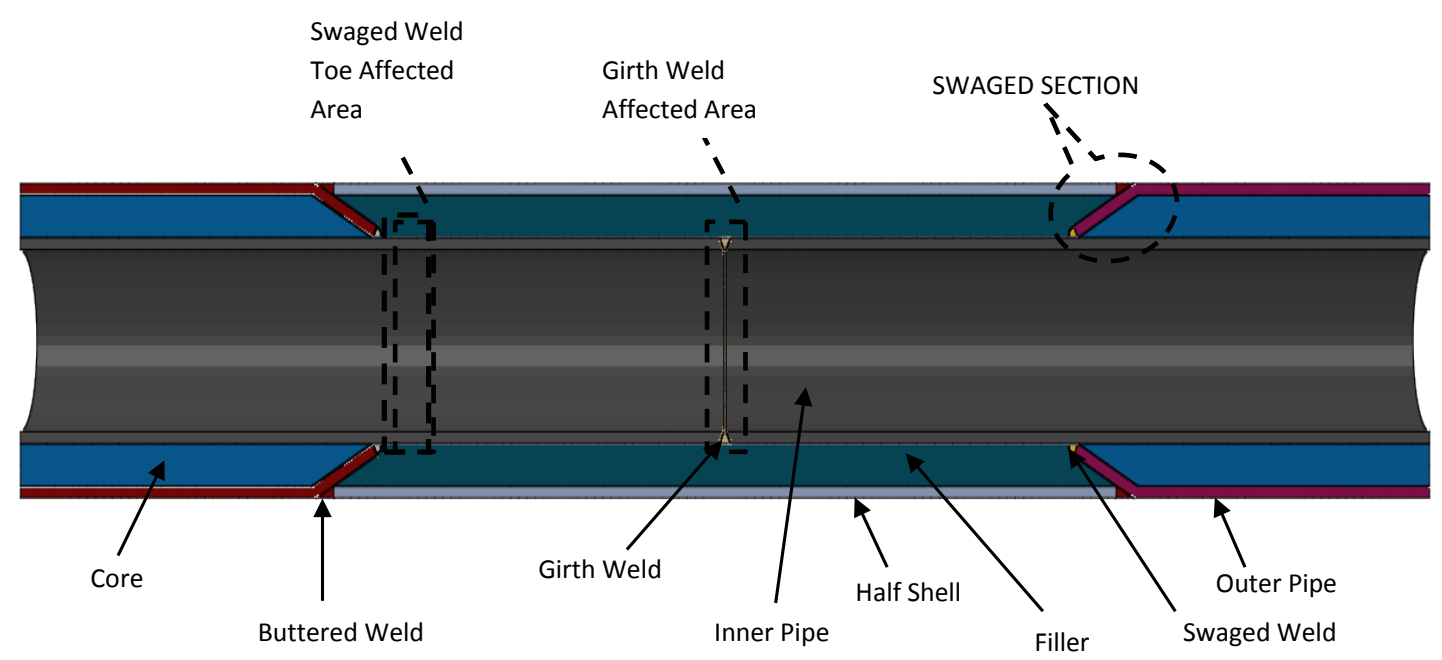

Figure 1. Sandwich pipe swaged joint

Due to the presence of a relatively stiff core in the assembly adjacent to the field joint and weld locations, one would expect the distribution of bending strains to differ from that in a conventional pipe-in-pipe system. One could review the sandwich pipe geometry as a single wall pipe with layered coating of the core and outer pipe, picking some similarities to work that has been done on bending of field joints used for subsea operations.

Geometric tolerances remain the most difficult hurdle to overcome in understanding the swaged field joint connections for pipe-in-pipe systems (Mallik et al., 2013). For this reason, this study would be investigating numerically, by means of finite element method, the response of sandwich pipe joints in relation to the inner pipe thickness, cutback length, ratio of filler to core stiffness, pipe yield strength and interlayer adhesion.

\section{Finite Element Modelling}

\subsection{Model Setup}

In other to gain in-depth understanding of the response of a sandwich pipe swaged field joint, a series of 3D FE models were developed using the commercial FE software Abaqus (Abaqus, 2014). Due to longitudinal and transversal symmetry of the joint geometry only a quarter of the swaged joint connection was modelled. The mechanical and geometrical properties of the model are listed in 
Tables 1 and 2, with steel properties matching those of API-5L (X65) used for both inner and outer pipes. A hi-lo of $1 \mathrm{~mm}$ at the inner pipe girth weld was assumed for all models.

Table 1. Mechanical properties for the model sandwich pipe

\begin{tabular}{|l|l|l|l|l|l|}
\hline Component & Material & $\begin{array}{l}\text { Young's modulus } \\
\mathrm{E}(\mathrm{GPa})\end{array}$ & $\begin{array}{l}\text { Yield strength } \\
\sigma_{y}(\mathrm{MPa})\end{array}$ & $\begin{array}{l}\text { Ultimate tensile } \\
\text { strength } \sigma_{U T S}(\mathrm{MPa})\end{array}$ & $\begin{array}{l}\text { Poisson's } \\
\text { ratio } v\end{array}$ \\
\hline $\begin{array}{l}\text { Inner Pipe, } \\
\text { Outer Pipe, } \\
\text { Half Shell }\end{array}$ & Steel & 207 & 448 & 603 & 0.3 \\
\hline Core & Polymer & 1.0 & $\begin{array}{l}\text { Perfectly } \\
\text { elastic }\end{array}$ & Perfectly elastic & 0.43 \\
\hline Filler & Polymer & 0.9 & $\begin{array}{l}\text { Perfectly } \\
\text { elastic }\end{array}$ & Perfectly elastic & 0.43 \\
\hline
\end{tabular}

Table 2. Geometric properties of the model sandwich pipe

\begin{tabular}{|l|l|l|}
\hline Inner pipe diameter & $D_{(i)}(\mathrm{mm})$ & 219.1 \\
\hline Outer pipe diameter & $D_{(o)}(\mathrm{mm})$ & 323.9 \\
\hline Inner pipe wall thickness & $t_{(i)}(\mathrm{mm})$ & 12.7 \\
\hline Outer pipe wall thickness & $t_{(o)}(\mathrm{mm})$ & 14.3 \\
\hline Half shell wall thickness & $t_{(h)}(\mathrm{mm})$ & 14.3 \\
\hline Core thickness & $t_{(c)}(\mathrm{mm})$ & 45.72 \\
\hline Cutback length & $L_{f}(\mathrm{~mm})$ & 350 \\
\hline Swaged angle & $\theta_{s}\left(^{\circ}\right)$ & 28 \\
\hline
\end{tabular}

An initial model was developed to represent the exact geometry of the physical system for a sandwich pipe swaged joint shown in Fig. 1. Although the geometry was precise, challenges included element distortion, especially for parts with varying thickness along the field joint length. A solution to this would be partitioning the part into multiple regions and applying variable mesh sizes. This strategy was adopted but only for regions of interest as although it would yield a more robust solution for the response of the joint if it were applied to the entire model, the computational cost would be enormous.

As an alternative, the geometry was de-featured to eliminate abrupt edges and high aspect ratio elements due to infinitesimal thickness. Localised regions of interest (swaged and girth weld 
interaction with joint assembly parts) were meshed separately to match fine regions of the weld metal with the coarser mesh of the other assembly parts.

The geometry of the swaged weld was adopted from experimental samples used in verification of the swaged weld method for joining insulated pipe-in-pipe (Mallik et al, 2013). Comparative studies showed that the de-featuring shown in Figure 2 does not affect the results of interest under the scope of this study; confirming observations drawn with similar study for pipe-in-pipe field joints (Mallik et al, 2013). Parametric studies were then carried out building from this confident FE framework to investigate the effect of key parameters on the SIF for the sandwich pipe field joint

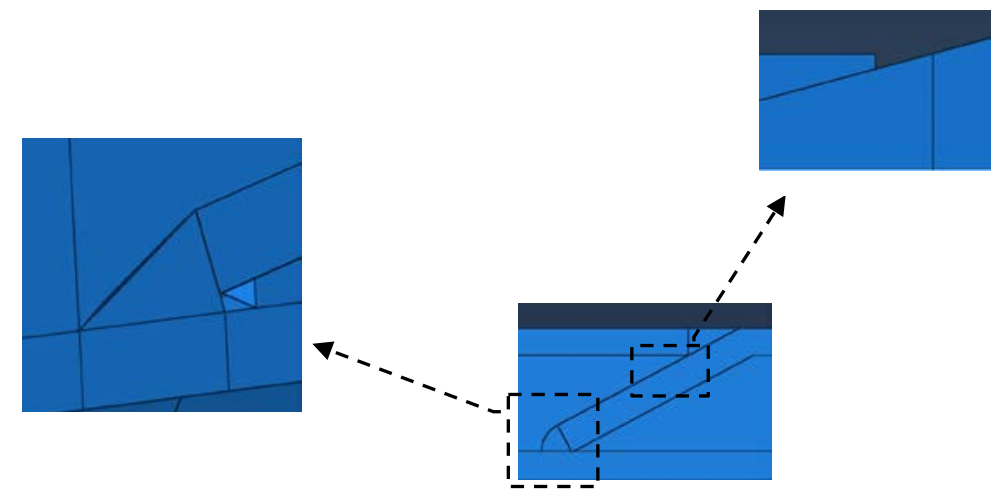

Figure 2. Improved geometry of swaged section

To verify mesh convergence, preliminary models of sandwich pipes without joints were built to compare with studies of sandwich pipes subjected to bending conducted by Arjomandi and Taheri (2012). The results showed that 44 elements in the circumferential direction were sufficient to predict the propagation of the strain field at the region of interest with a difference of $0.00001 \%$ in maximum longitudinal strain experienced at the field joint region. This generated a larger difference of $0.001 \%$ at yield and post-yield curvatures. Consequently, a second sensitivity study was carried out and found that 52 elements in the circumferential direction would yield a difference of approximately $0.0002 \%$. Due to the complex geometry of the assembly, the number of longitudinal and through thickness elements were chosen to avoid mesh locking and distorted elements especially in regions of interest. Local finer meshes had to be employed at weld interfaces within the model to properly capture the interaction especially at the swaged and girth weld regions. 
Due to lack of previous experimental work on this joint assembly, comparative FE models were developed to verify the proposed FE framework. The validity of the FE framework used in this study was established by reading off pipe-in-pipe reeling experimental results as carried out in study by Jones et al. (2013) using a 7.5m radius reel former. The experiment yielded strain gauge readings for the reeling and straightening of pipe-in-pipe, although only the bending results representing the former curvature were considered (static analysis). The validation FE model was built to exact dimensions as described in the experiment (Fig. 3a) and the location of the strain gauges were captured by results read off node paths. As only 5 strain gauge measurements were published along the outer surface of the inner pipe, the validation model was designed in like manner. The strain values generated by the validation model showed close semblance to the strain gauge readings especially in the cut back region. Being that the strain gauge values represent averaged strains over the extent of the gauge and the validation model results represent spot on FE predictions of the strains, one can consider the comparison a reasonably good one. Also, the maximum longitudinal strain as predicted by the validation model (4.11\%) fits right with the experimental result $(4.02 \%)$. The longitudinal strain distribution along the length of the pipe is shown in Fig $3 b$, where the dark spots represent the experimental strain gauge values. This conclusion further strengthened the framework of the FE model for accurately predicting the longitudinal strains in this study.
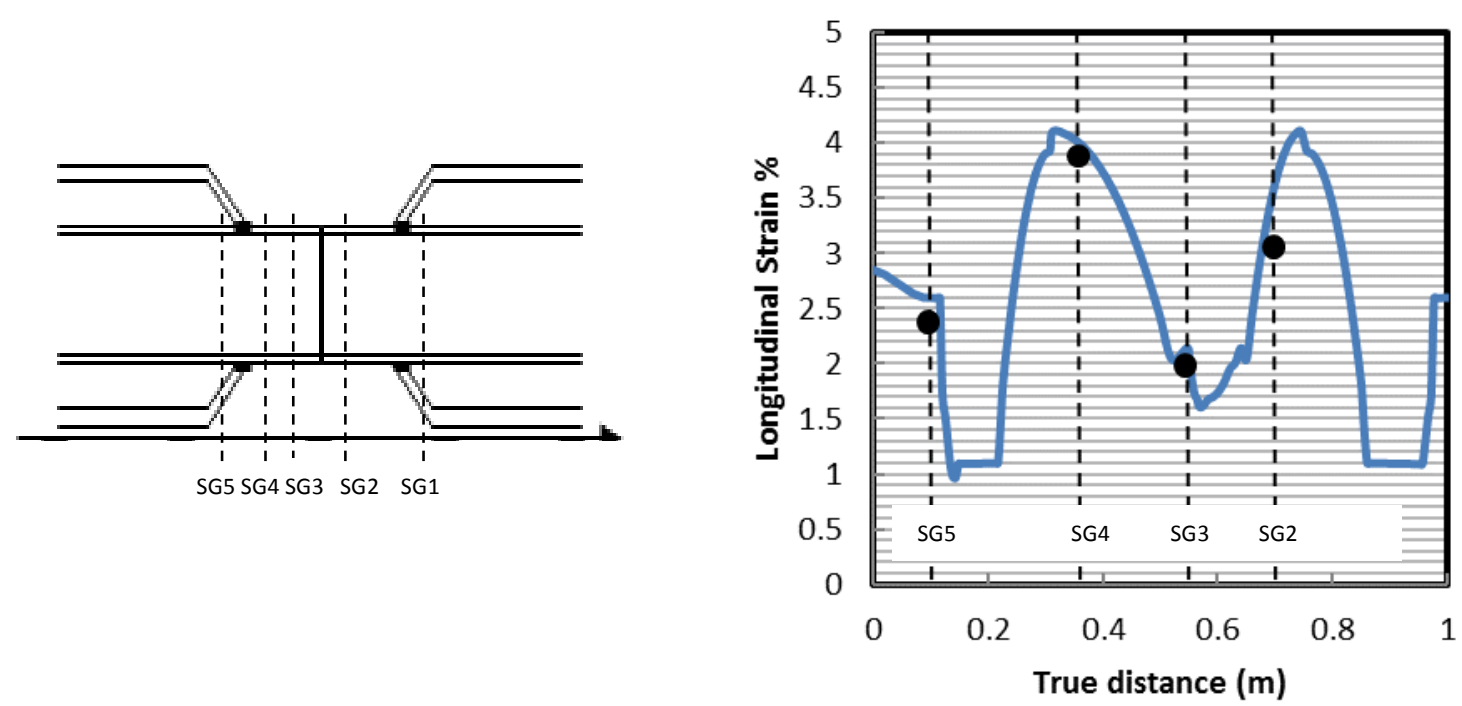

Figure 3: (a) Strain gauge locations along inner pipe; (b) Longitudinal strain variation

The mesh for the steel parts was generated using 3D solid elements C3D2OR (20-node quadratic brick with reduced integration) which model bending dominated problems effectively and prevents 
the issue of shear locking which is usually associated with full integration elements undergoing bending deformation (Abaqus, 2014). With assumption of volumetric incompressibility, the core polymeric layer was meshed with $\mathrm{C} 3 \mathrm{D} 2 \mathrm{OH}$ elements to solve independently the pressure stress as a basic solution variable before coupling to the displacement solution to avoid singular behaviour arising from using overly sensitive displacement based solution to capture deformation in the annular material.

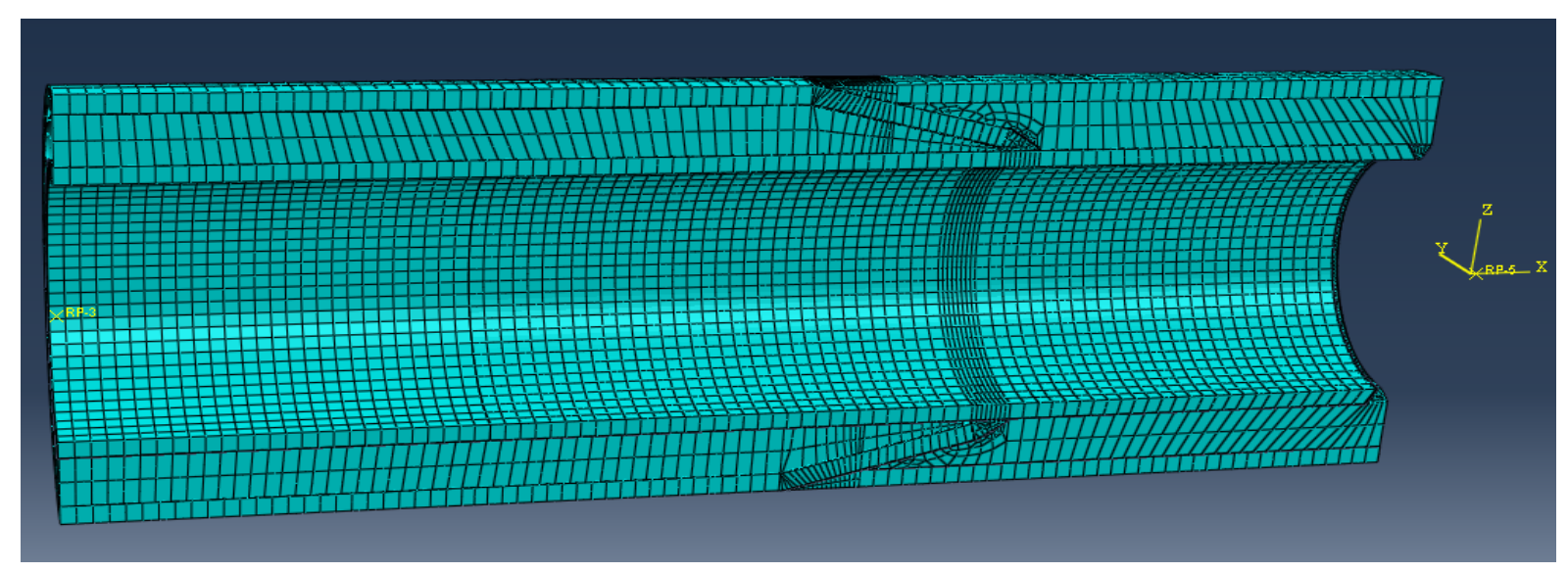

Figure 4. Finite element mesh of a sandwich pipe swaged joint

Bending is applied to the joint assembly by nodes at the end pipe cross section modelled as rigid bodies and associated with a master node located at the neutral axis to which the rotational displacement boundary condition is applied. The node is associated with the rigid nodes using a multi-point tie constraint to ensure that the nodes have both translational and rotational degrees of freedom associated with the master node. Automatic increment control in a static step was employed to perform the bending which covered nonlinearities in geometry deformation. As it is a study of pure bending, post weld heat treatment or hot field joint coating effect on the material properties of the inner and outer pipes are ignored.

For all models considered in this study a maximum curvature corresponding to bending on a $6 \mathrm{~m}$ diameter reel drum (smallest reel drum used up to date) was applied to cover a range of curvatures associated with offshore pipeline installation. The relationship between the pipe length, rotational displacement and applied curvature is expressed by Eq. (3).

A $10 \%$ yield strength overmatch was used to model the welds to allow for strain intensity due to modified stiffness at the weld interface with parent pipe. Post yield behaviour for the steel layers 
was modelled by $\mathrm{J} 2$ plasticity theory with isotropic hardening with true stress-strain data evaluated by an elastic response followed by a Ramberg-Osgood plasticity response as shown below:

$\varepsilon=\left\{\begin{array}{l}\frac{\sigma}{E} \text { if } \sigma<\sigma_{y} \\ \frac{\sigma}{E} *\left[1+\frac{3}{7}\left(\frac{\sigma}{\sigma_{y}}\right)^{n-1}\right] \text { if } \sigma>\sigma_{y}\end{array}\right.$

Ramberg-Osgood model was used to capture the plastic strains with the strain index fitted from experimental results carried out on X65 pipes by Liessem et al. (2007) with an index $n=19$.

\subsection{Parametric studies}

The variation in strain concentration has been studied for the swaged weld and girth weld regions by running a series of FE models to investigate the influence of the cutback length $L_{f}$, the filler to core stiffness ratio $E_{f} / E_{c}$, the weld metal to pipe metal yield strength ratio $\phi$, the intra-layer adhesion property and the diameter-to-thickness ratio $D_{(i)} / t_{(i)}$.

The influence of the cut-back length on the strain concentration was studied by considering parameter $r_{i} / L_{f}$, which is the ratio of the inner pipe radius to the cutback length. In pipeline design, the cutback length is not a standard but varies depending on the type of loading expected at the joint and the residual stresses imposed by the heat affected zone (Zandberg and Ladyzhanskii, 2005). For concrete coated pipelines, some generally accepted length settles at around $35 \mathrm{~cm}$, but it usually involves design considerations driven by both physical and numerical testing.

As mentioned earlier, the variation in bending stiffness between two adjacent regions in a pipe assembly is the main determinant of the extent of strain concentration under pure bending and as such the influence of mismatching the yield strength of the pipe and weld materials on the SIF was studied using the parameter $\phi$, as defined below:

$\phi=\frac{\sigma_{y}^{w}}{\sigma_{y}^{p}}$

where $\sigma_{y}^{w}$ and $\sigma_{y}^{p}$ represent the yield strength of the weld and the pipe material, respectively.

The adhesion properties between the layers of both the pipe and joint assembly has been studied previously by Arjomandi and Taheri (2012) and shown to significantly influence the structural and 
load bearing capacity of the sandwich pipe. To consider intra-layer adhesion in this study, the swaged weld connection for sandwich pipes is categorised into four scenarios namely:

- Perfect adhesion between all joint component inter-layers and also between inner- coreouter pipe surfaces. This will be denoted by FB.

- Perfect adhesion between inner- core-outer pipe surfaces with sliding allowed to occur between the inter-layers at the field joint region. This will be denoted by FJ-NB.

- Perfect adhesion between inter-layers at the field joint region and sliding can occur between the inner-core-outer pipe surfaces. This will be denoted by C-NB

- Free sliding between all joint components inter-layers and inner-core-outer pipe surfaces. This is denoted as A-NB.

Perfect adhesion was defined in the finite element models using the surface to surface formulation of a tie constraint in Abaqus for which the translational and rotational degrees of freedom of the slave surface nodes are replaced by those of the master surface nodes. The free sliding interaction was defined by surface-to-surface contact interaction in Abaqus using a frictionless tangential relation and a linear penalty relation to define normal behaviour in contact.

\section{Results and Discussion}

\subsection{Strain Analysis}

Longitudinal strain distribution along the length of the inner pipe is shown in Figure 5 starting from the girth weld interface. The average longitudinal strains along the length of the pipe for a range of $\varepsilon_{g}$ values are presented, with position schematics indicating high strain regions along the length. As is expected, strain localisation at the girth weld interface due to weld-pipe metal mismatch and hi-lo is observed and expected according to previous studies on strain intensity at girth welded pipes (Sriskandarajah et al, 2003). Moving further away, the strain appears constant and then elevates signifying the beginning of the stiffening enhanced region due to the presence of the swaged weld. The swaged weld can be characterised as a stiffener ring acting on the surface of the inner pipe thus allowing for higher strain just adjacent to the weld toe as can be seen in Figure 5. 


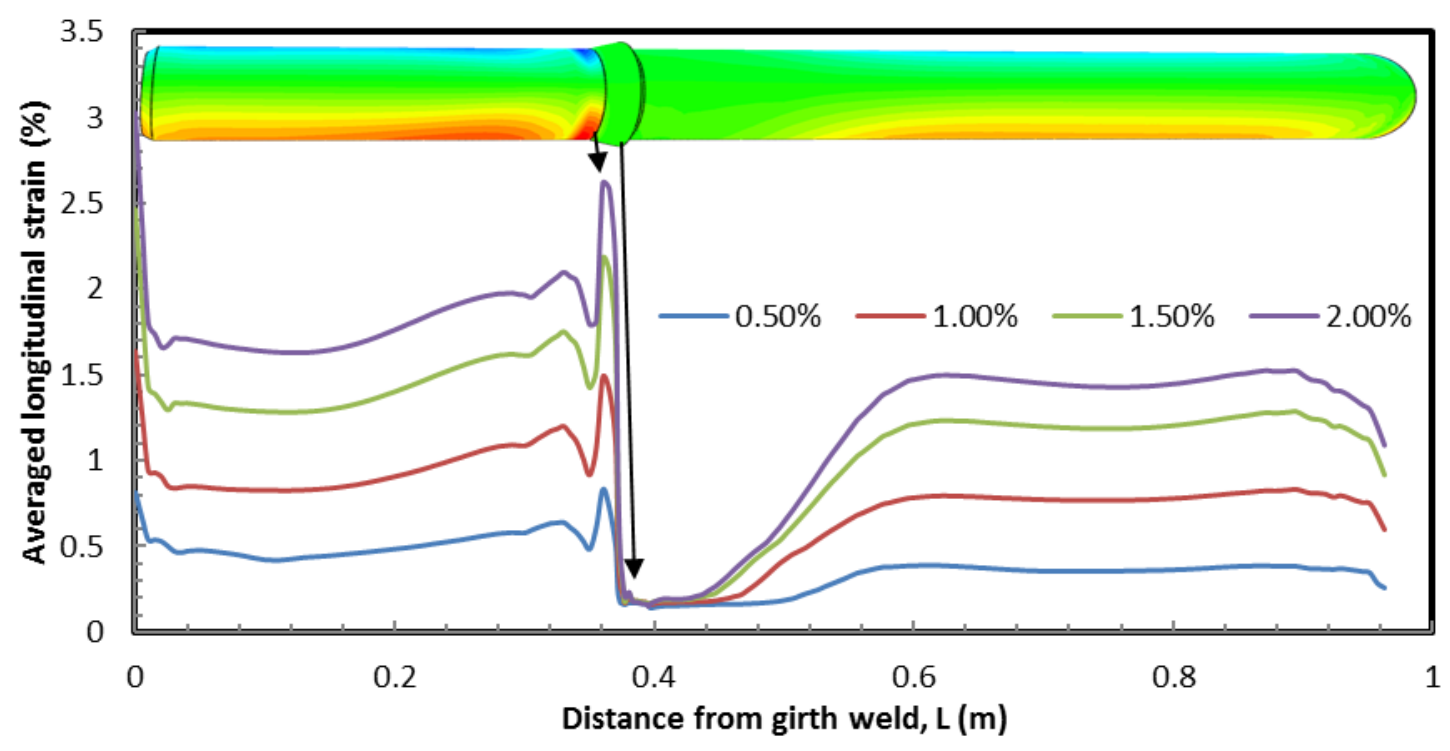

Figure 5. Strain variation along the pipe for a range of global strain values

These strains would peak before the swaged weld - inner pipe interface where the strains observed are the lowest along the length due to the enhanced bending stiffness at that region. The geometrical properties of the swaged weld would be of significance to the localised response at this region (Mallik et al, 2013) but that is not parametrically taken into consideration in this study. As we observe, the strains begin to increase as we move a definite distance from the swaged weld due to the fading of the stiffness advantage. This represents a length on the inner pipe at which the sandwich pipe assembly can bend as a compact unit thus producing close-to-uniform strain distribution along the length which will be due to lesser bending strains. The drop in averaged strains was due to the boundary conditions at the pipe ends.

From the analysis of strain variation, it becomes clear that the two regions of highest strain concentration in the inner pipe would lie just adjacent to the swaged weld toe and girth weld cap. For this reason, subsequent analysis will focus primarily on the following two regions of the inner pipe: the Swaged Weld Toe region (SWT region) and the Girth Weld Cap region (GWC region), as marked out in Fig. 6. 


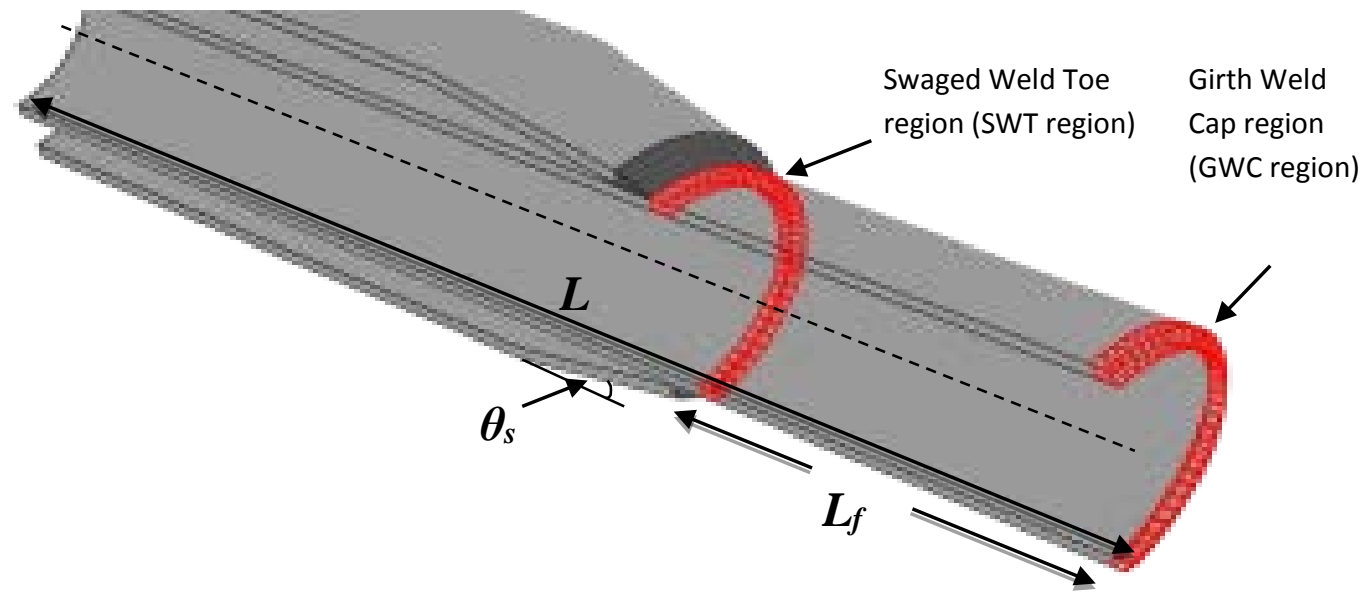

Figure 6. Sandwich pipe swaged joint showing regions of interest of the inner pipe

In an ideal case of a single pipe bending elastically, the strain concentration is usually situated at the apex of the bend where failure due to an increase in ovalisation would normally take place (Kyriakides and Corona, 2007; Chen et al, 2016). In the presence of a girth weld, the Brazier's effect would still hold, and the location of maximum strains will lie either in the weld region or adjacent pipe depending on the difference in bending stiffness between the two sections. The swaged weld acts as boundary of higher bending stiffness (like a stiffener ring) when the curvature is applied and as such resolving the bending stress at its section will translate to higher strains at the adjacent inner pipe due to its lower bending stiffness. This phenomenon is common for most of the analysis results, varying in magnitude from one parametric study to another.

The general relationship between the SIF in the inner pipe regions adjacent to the swaged weld (SWT region) and girth weld (GWC region) and the global strain is shown in Fig. 7. The zones are mainly characterised by their upper bound global strains $\varepsilon_{g}$ as shown in Table 3 . 


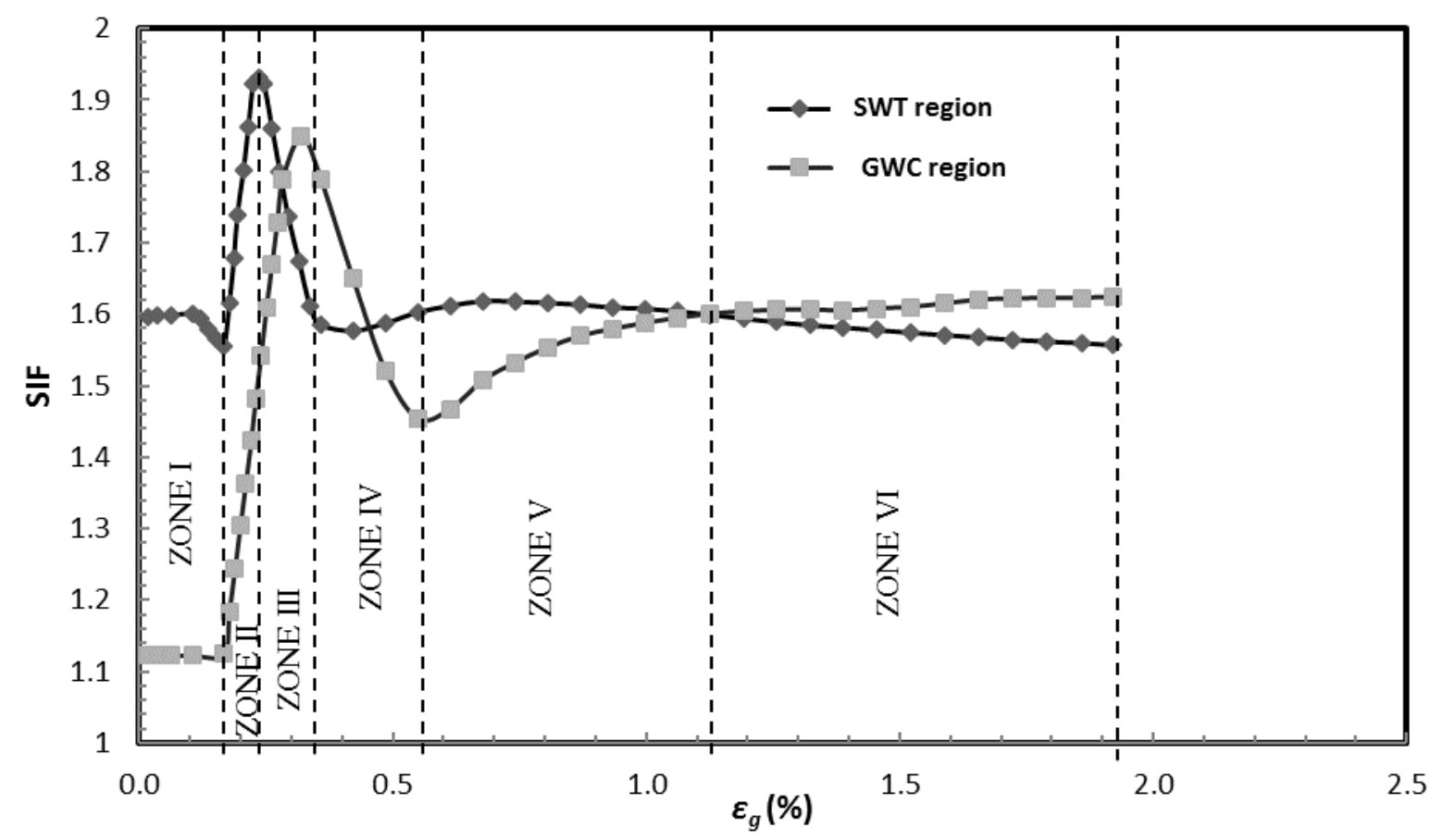

Figure 7. Variation of SIF with global strain for regions of interest

Table 3. Strain Nomenclature

\begin{tabular}{|l|l|l|l|l|l|l|}
\hline & Zone I & Zone II & Zone III & Zone IV & Zone V & Zone VI \\
\hline$\varepsilon_{g}(\%)$ & $0-0.18$ & $0.18-0.25$ & $0.25-0.35$ & $0.35-0.55$ & $0.55-1.13$ & $1.13-2.00$ \\
\hline
\end{tabular}

At the onset of bending the SIF remains constant as the global strain increases for both regions of interest. A little drop in SIF can be observed in Zone I for the SWT region signifying the global strains at which the applied curvature is not large enough to translate sufficient bending strains in the longitudinal direction past the swaged weld to cause the inner pipe region adjacent to the swaged weld toe to act as a single pipe undergoing the same curvature. The inner pipe also exhibits elastic behaviour at this stage similar to what will be expected at the sagbend for deepwater installation.

On increasing $\varepsilon_{g}$ SIF increases rapidly signifying the onset of plastic deformation in the inner pipe in the SWT region, with global strain in Zone II; this is typical for pipelines installed using a stinger. At this point the joint system undergoes some moment instabilities.

It should be noted that the first region of moment instability due to the applied curvature occurs at the swage deflection region (outer pipe). Once plastic deformation is experienced in the inner pipe, the swaged weld stiffener effect is significantly in play and the inner pipe exhibits higher strain 
concentration due to localised plasticity with the swaged weld toe acting as a hinge point. One reason for this is that the swaged weld acts as a boundary constraint to the bending deformation on the outer surface of the inner pipe thereby serving as a hinge which obstructs the free bending strains on the outer surface thus harbouring residual strains due to the change in stiffness profile at the swage weld. Since the swage weld interface with the inner pipe represents the area of largest variation in bending stiffness along the inner pipe the strains at this region represent the highest strains that was recorded through deformation (this is dependent on cut-back length as we will see further).

As $\varepsilon_{g}$ increases, the SIF value significantly drops again (Zone III) signifying the onset of plastic deformation for the swaged weld; this relaxes the localised plasticity effect on the strain concentration in the SWT region. SIF then slightly increases due to the material mismatch (weld and parent pipe) before dropping almost linearly as the curvature increases, which from the results indicated a higher strain concentration in the GWC region. The same phenomenon occurs in the GWC region with the major difference being the global strain values at which the onset of localised plasticity occurs for both the inner pipe interface with the girth weld and the girth weld metal. In practice, SIF in the GWC region will also be influenced by eccentricity and hi-lo (Hooper et al., 2004). It can be seen that the rapid increase caused by localised plasticity is of a higher magnitude in the GWC region because at the corresponding curvature, the swaged weld has undergone yielding greatly reducing its stiffener effect due to bending stiffness differential. This allows the entire inner pipe length to adopt a bending response similar to a single pipe which will undergo Brazier's effect. This sudden release of strain energy allowed to flow through the length of the inner pipe magnifies the strain concentration in the GWC region. Also, it can be seen that the point where the swaged weld fully yields is coincident with the point at which the girth weld begins to yield. This point also represents the global strain at which the curvature is high enough to propagate the whole length of the inner pipe. SIF then drops as seen similarly to the SWT region as a result of yielding of the girth weld metal but then increases again due to the entire joint components being passed their moment capacity. At this stage, the field joint region can bend in some uniform way which means that ovalisation is localised at the apex of the bend and the maximum strains are located in the GWC region. This can be seen at the termination line for Zone $V$ (strain levels common for reeled pipelines); a point at which the entire joint assembly begins to behave as a single unit and ovalisation is completely localised at the bend apex, as the SIF in the SWT region slides downwards and that in the GWC region glides upwards with increasing global strain (Zone VI). 


\subsection{Effect of Inner Pipe Thickness}

The influence of the inner pipe's thickness as studied by its diameter-to-thickness ratio $D_{(i)} / t_{(i)}$ on the SIF is illustrated in Fig. 8. All other geometrical and mechanical properties are kept the same as described in the model case, including the properties of the swaged weld. Increasing the inner pipe's thickness would increase its bending stiffness; as the properties of the swaged weld remain unchanged, the variation in bending stiffness in the SWT region is reduced and thus the SIF would drop with reducing the $D_{(i)} / t_{(i)}$ ratio. The effect of $D_{(i)} / t_{(i)}$ on the SIF is most significant along the strain path that represents inner pipe yielding showing once again the effect of the pipe's thickness on the bending stiffness. Although increasing the inner pipe thickness can help handle strain concentration issues in the SWT region, other considerations like the pipes' weight, pressure capacity requirement, girth welding complexities, etc. ( Bai and Bai, 2014) can restrict the significance of using the inner pipe's wall thickness as a controlling property for SIF for offshore sandwich pipe installation.

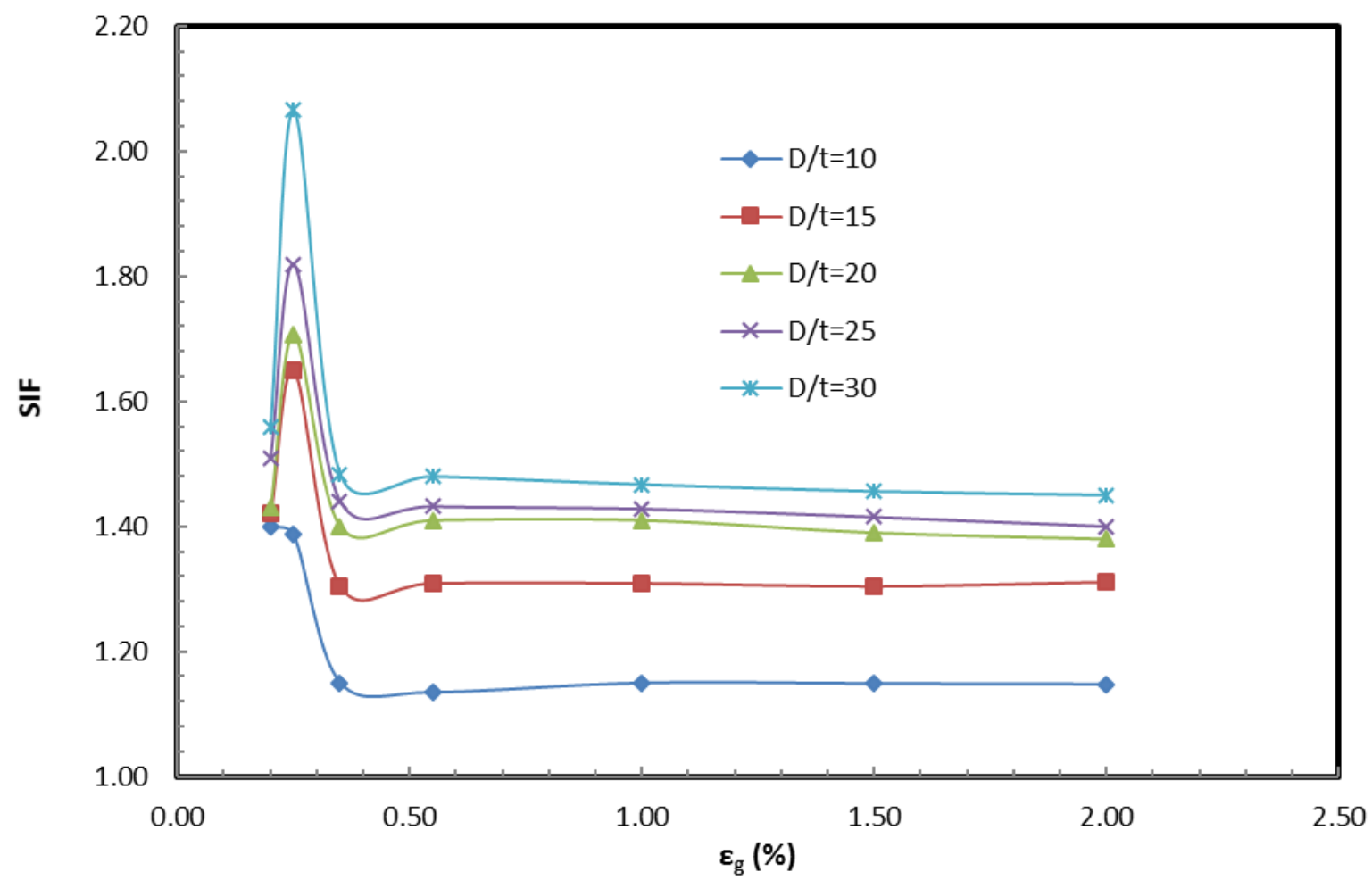

Figure 8. Effect of $D / t$ on SIF for the SWT region

\subsection{Effect of Filler-to-Core Stiffness Ratio}

Figure 9 shows SIF as a function of the global strain $\varepsilon_{g}$ for a range of filler-to-core stiffness ratios $E_{f} / E_{c}$. The SIF is taken in the SWT region as the swaged weld is positioned adjacent to both 
materials. For the SWT region, the variation in SIF becomes significant from Zone III with increasing magnitude as $\varepsilon_{g}$ increases. This goes to show that after the yielding of the swage weld metal, the stiffness of the filler has a fairly significant effect on the strain intensity for pure bending. This effect would be less significant with the application of a back tension as in the case of pipeline reeling.

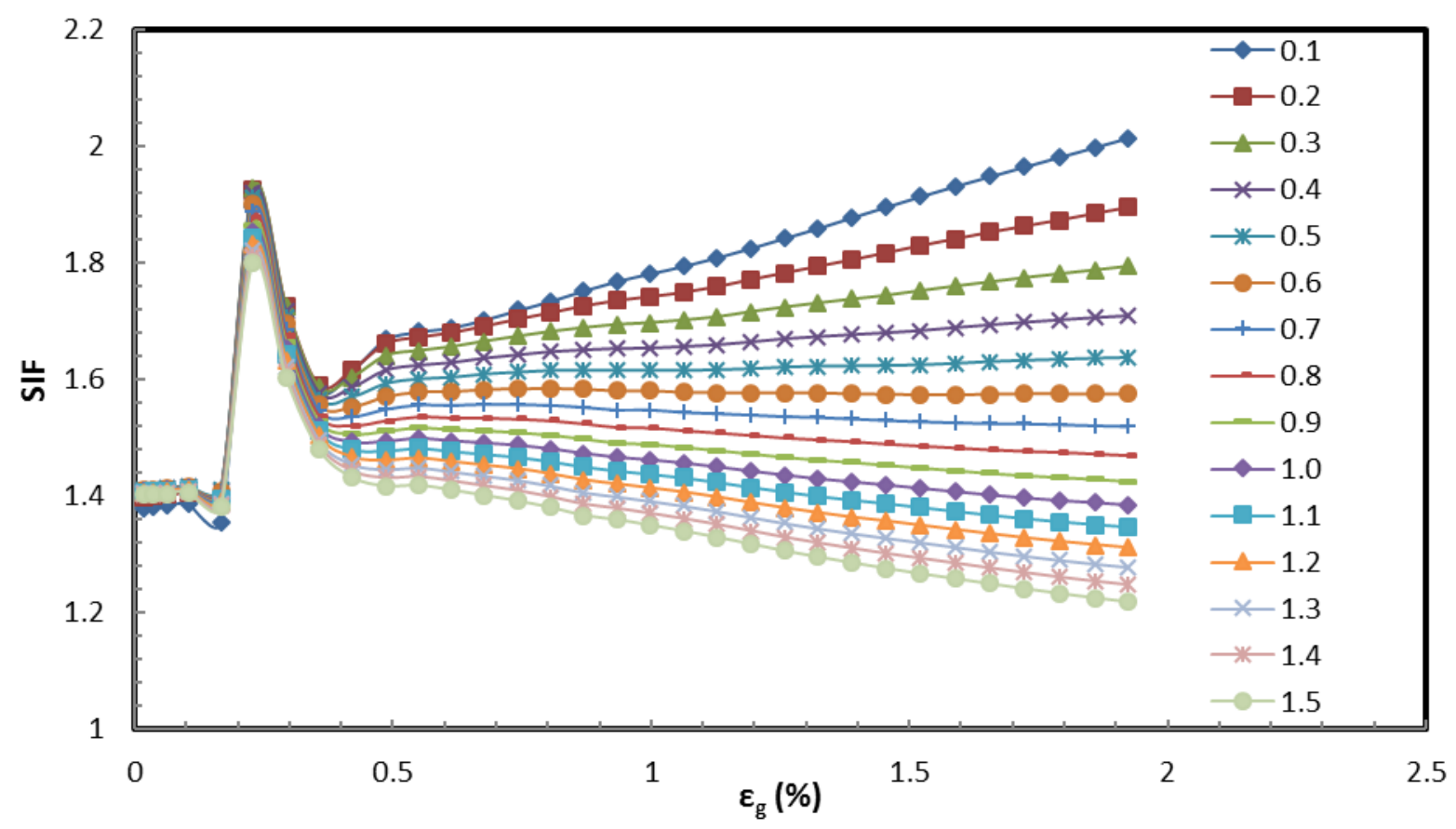

Figure 9. Strain intensity factor in the SWT region as a function of global strain for a range of filler-to core stiffness ratios

In the SWT region, the SIF reduced with increasing $E_{f} / E_{c}$ with the SIF moving stepwise (0.1-1.5) from a positive slope trend to a negative slope trend from Zone III with increasing $\varepsilon_{g}$. The results further go to show that the structural properties of the filler material play a more significant role in enhancing the mechanical response of the sandwich pipe assembly with the steel pipe undergoing deformation in the plastic region as long as the core material is offering a significant structural advantage to the assembly.

As shown in Fig. 10, the SIF remains constant irrespective of the applied curvature for $E_{f} / E_{c}=0.6$ from Zone IV which represents the curvature at which all pipe joint components have undergone yielding and ovalisation becomes the major determinant of the high stress regions within the inner pipe. From a design point of view, it would be advisable to select materials that satisfy $E_{f} / E_{c}>0.6$ as materials that fall below this point tend to exhibit steadily rising SIF as for greater curvatures. 
Comparative analysis showed that in the GWC region, as $E_{f} / E_{c}$ increased the SIF reduced, exhibiting similar effect as recorded by work on pipelines with thick insulation coating by Roberts et al (2009).

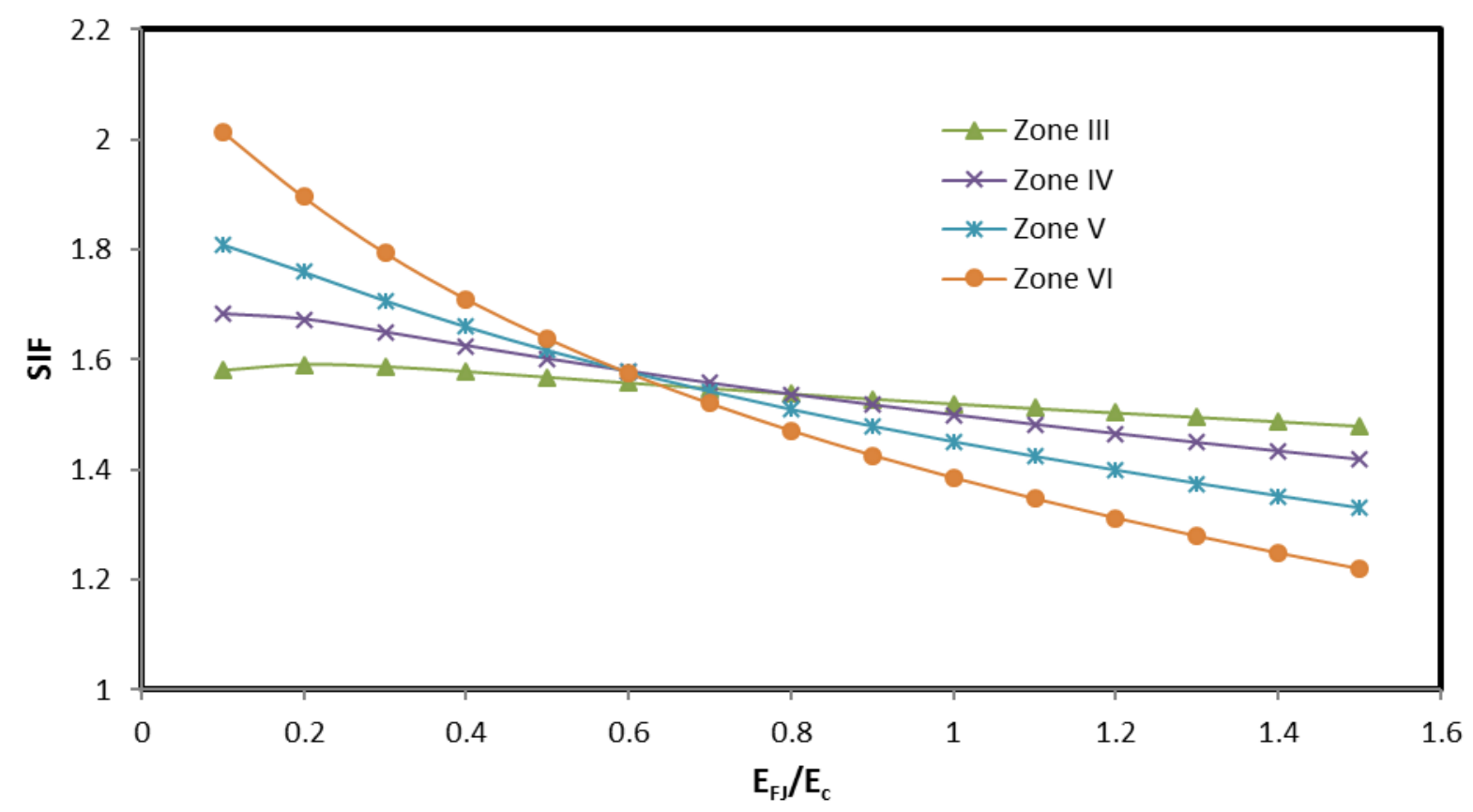

Figure 10. Strain intensity factor in the SWT region as a function of filler-to-core stiffness ratio for a range of global strain zones

\subsection{Effect of Cutback Length}

The effect of the cutback length on the strain concentration of a conventional swaged sandwich pipe joint is generally different from that expected for concrete coated pipe or wet insulation pipelines. This is due to the complex geometry and varying sectional profiles and properties as seen in Figs. 11, 12 and 13. 

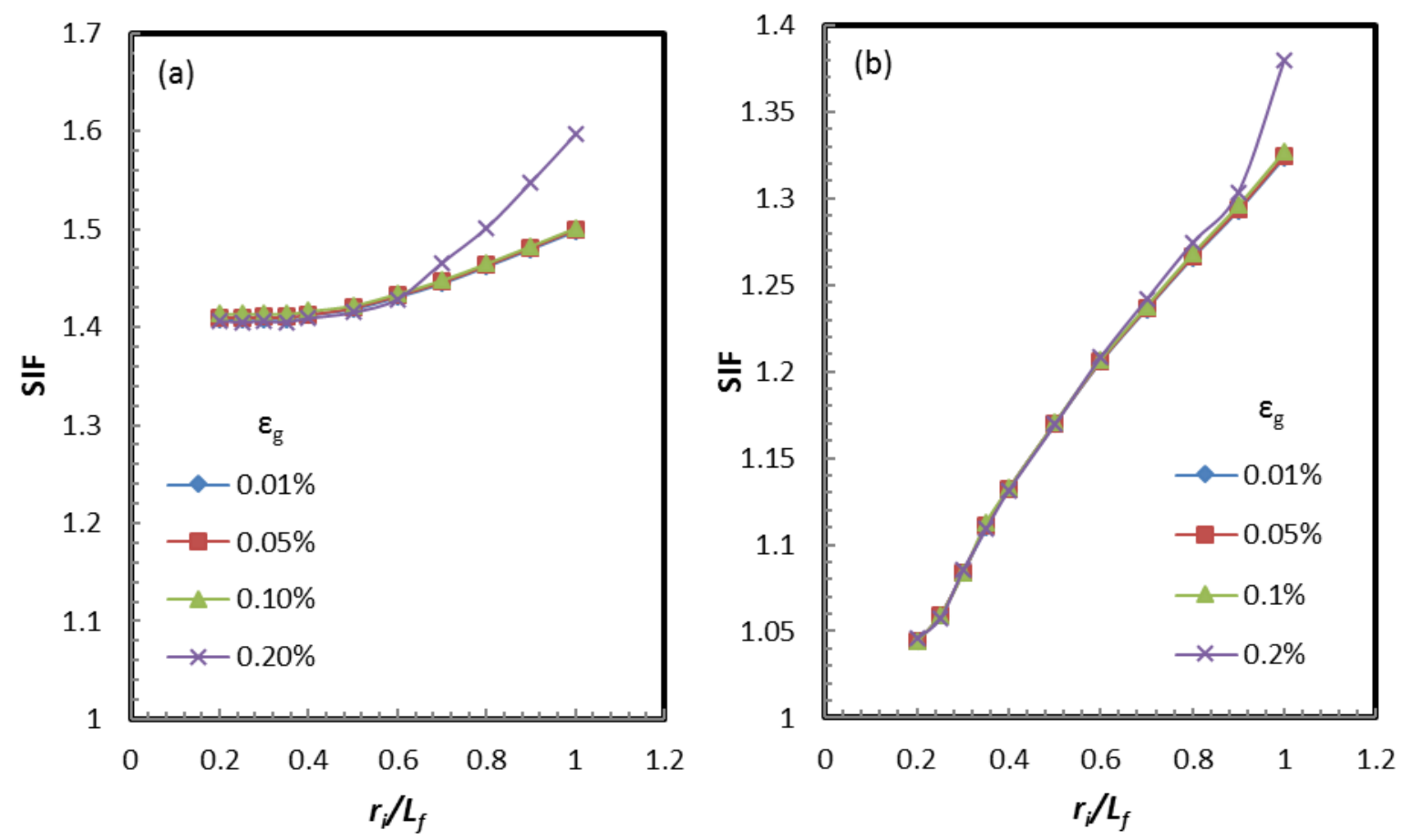

Figure 11. Effect of cutback length on SIF for Zones I and II: (a) SWT region (b) GWC region
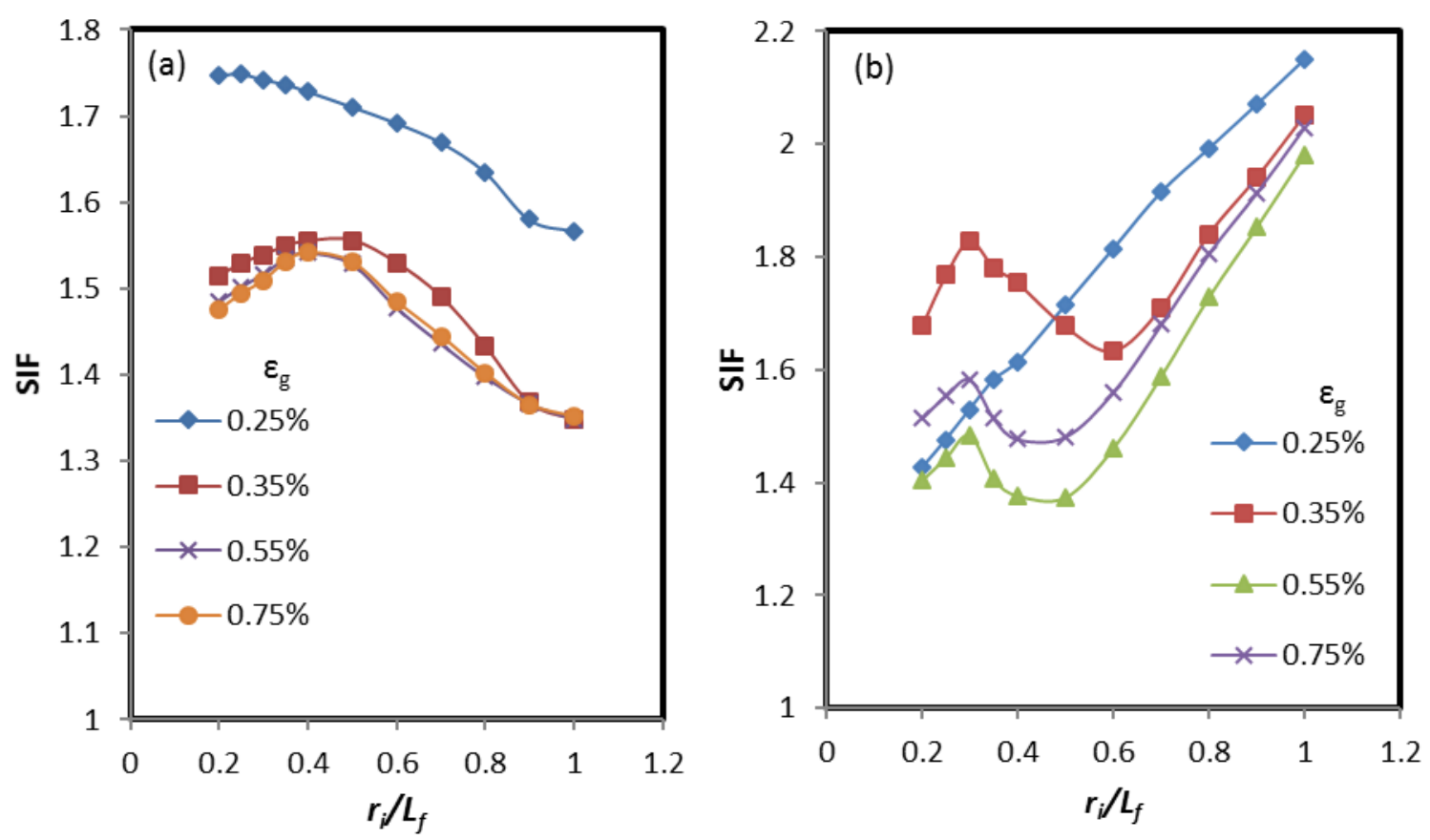

Figure 12. Effect of cutback length on SIF for Zones III and IV: (a) SWT region (b) GWC region 

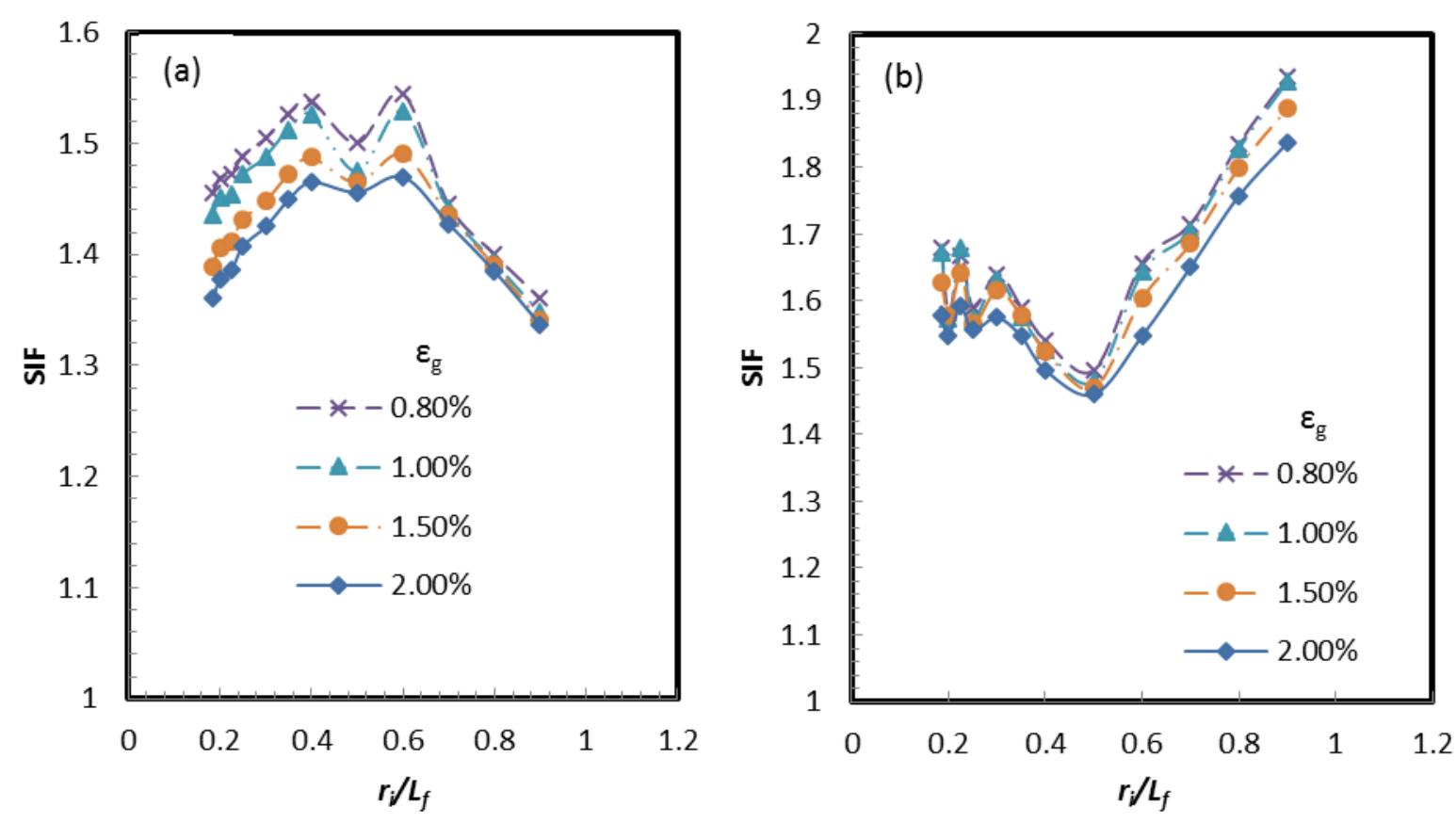

Figure 13. Effect of cutback length on SIF for Zones V and VI: (a) SWT region (b) GWC region

The applied curvature was kept constant for all cases by adjusting the length term in Eq. (3). Up until the onset of yielding in the SWT region, the SIF shows no significant variation up to $r_{i} / L_{f}>0.6$. The GWC region experiences higher magnitude variations in SIF as $r_{i} / L_{f}$ increases for all global stain values considered with a leap in SIF at $r_{i} / L_{f}=1.0$ which goes to show that the cut back length can be short enough to cause an early yield in the inner pipe in a sandwich pipe assembly and also goes to show that for lower values of $L_{f}$ the SIF will be amplified for both regions.

It can be seen in Fig. 12 that the yielding of the swaged weld metal $\left(\varepsilon_{g}=0.25\right)$ causes SIF to drop for the SWT region and increase for the GWC region for all $r_{i} / L_{f}$ used in this analysis. This further shows that the magnitude of the strain relief caused by the yielding of the swaged weld metal has a direct relation to the magnitude of strain intensity caused by the yielding of the parent pipe in the GWC region with the cutback length being a relation constant. This further goes to show that the swage joint connection for a sandwich pipe will not act as a compact assembly when undergoing pure bending and this makes its analysis even more complicated. In the GWC region, the maximum SIF throughout these zones occur at $r_{i} / L_{f}=1.0$ and parent pipe yielding occurs at a lower $\varepsilon_{g}$ value for $r_{i} / L_{f} \geq 0.5$ than $r_{i} / L_{f}<0.5$. This is because of its proximity to the swaged weld and the short transfer zone of the longitudinal strain bands that will appear on the outer fibre of the pipe due to the localised plasticity cause by the yielding of the parent pipe adjacent the SWT region. 
For Zones V and VI (Fig. 13), as the cutback length decreases we can see a generally convex relationship with the SIF in the GWC region and a concave relationship with the SIF in the SWT region. It can be observed that for ratios $r_{i} / L_{f}>0.6$ the strain intensity is concentrated in the GWC region. This goes to show that the swaged weld stiffener effect is lost gradually as the two regions become closer after the yielding of the swaged weld. As the SWT region and GWC region get closer, the longitudinal strain bands from the two regions intersect, amplifying the SIF in the GWC region which is further aided by the Brazier's effect. This is due to the complex geometry of the sandwich swaged joint as the weld between the outer pipe and the half shell plays an important role in the overall bending response of the swaged joint (Jones et al., 2013), although it is out of the scope of this paper. It can be seen from Zones III, IV, V and VI that increasing $\varepsilon_{g}$ would lead to a reduction in SIF. This would normally be an anomaly but not in the plastic region as the deformation slope is similar for all components that make up the sandwich pipe assembly. Also since the outer pipe and half shell are not analysed in this study one would not be able to accurately predict their influence on the SIF in the SWT region and GWC region except from general observation that yielding occurs firstly at the deflection edge that forms the swage on the outer pipe and the maximum longitudinal strains at final curvature would occur at the half shells. From result comparison through the zones it can be affirmed that design considerations should start from $r_{i} / L_{f} \leq 0.4$ as it represents a cut back length at which the mechanical response of the two regions is favourably isolated, although other considerations like the designing to ensure close matching stiffness and length of half shell would most likely make having really low values for $r_{i} / L_{f}$ unfavourable.

\subsection{Effect of Weld Property}

The effect of the weld property was studied to ascertain its influence on the SIF. It is common industry practice to use weld procedures and materials that produce a connection with slightly higher toughness than that of the adjacent parent pipe (Sriskandarajah et al, 2003). This is done by using an electrode and welding technique that produces a weld overmatching the pipe's yield strength by a factor. This study considered $\phi$ values between $0.9-1.5$ representing $10 \%$ undermatch to $50 \%$ overmatch. 


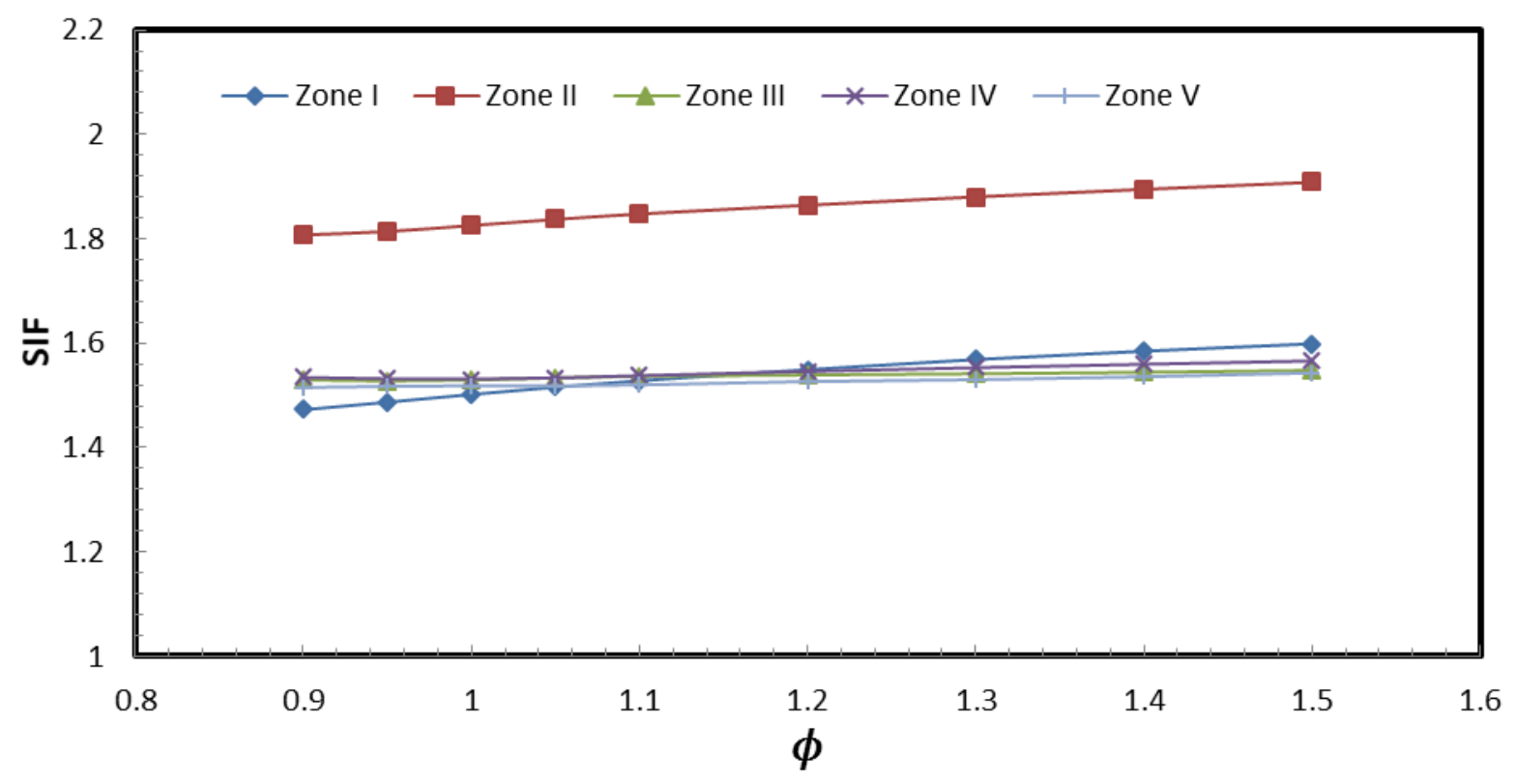

Figure 14. Effect of weld property for a range of global strain zones

From the analysis of results, it can be noticed that $\phi$ has little significance on the SIF in the SWT region with the exception of deformation occurring at Zones I and II. This is believed to signify the point of inner pipe and swage weld metal yielding respectively. It can be seen from Fig. 14 that the SIF increases as $\phi$ increases due to the swage weld being tougher and acting as a better hinge for localised plasticity in the inner pipe. This further goes to verify that the yielding of the swaged weld kicks off at Zone III. Although recommended industry practice would suggest specifying a weld metal tougher than that of the adjacent parent material, it is not always advantageous as can be seen from the results. This further goes to show that the geometry and weld properties in a swage joint connection for sandwich pipes will be a trade-off between the weld metal toughness and SIF at the swaged weld (full penetration fillet weld) - inner pipe interface as far as integrity management for the inner pipe is concerned.

\subsection{Effect of Inter-layer Adhesion}

The effect of the adhesion condition between the joint components on the SIF in the SWT region is shown in Fig. 15 and 16 for the four scenarios, outlined in Section 3.2. It can be seen that the fully bonded condition would produce the highest SIF all the way from the onset of bending till after the yielding of the swaged weld. For elastic bending around the regions of interest very little difference was observed between the FJ-NB, C-NB and A-NB configurations whereas on the yielding of the 
inner pipe in the SWT region the SIF for the configurations stand at FB>FJ-NB>C-NB>A-NB with all showing a positive slope indicating that the localised plasticity effect that causes the SIF to increase has the highest impact for FB and lowest impact for A-NB. This is because for A-NB, the isolation of the swaged region into disbanded layers reduces its stiffness as a unit (He et al., 2015) and reduces the bending stiffness differential between it and the SWT region. Similar response is seen for global strains defining the yield of the swaged weld metal, with FB showing the largest reduction in SIF for all configurations considered. As $\varepsilon_{g}$ increases, R-NB and A-NB exhibit a rise in SIF while FB and C-NB exhibit a drop in SIF. The drop in SIF is not an anomaly as C-NB experiences an increased strain concentration at the swage deflection point on the outer pipe due to the reduced bending capacity which is caused by the disbandment of the core. This also reduces the bending stiffness differential in the SWT region and inevitably leads to a reduction in the SIF as $\varepsilon_{g}$ increases. This is also one of the reasons why the SIF for FB exhibits a fairly constant response as $\varepsilon_{g}$ is increased. Disbandment of the field joint filler means a higher differential in bending stiffness between the swaged region and the SWT region and on increasing $\varepsilon_{g}$ the effect is amplified as the field joint region doesn't bear the resulting moment together as a unit. Same response is seen for A-NB but with lower SIF than R-NB because disbandment at both the swaged region and the SWT region means a reduction in bending stiffness for both regions with the slight mechanical (filler and core elastic modulus) and geometrical (swaged weld shape) changes driving the SIF in a positive slope. The observations here align with experimental work by Mallik et al (2013) which found that for configurations with unbounded resin, higher stresses will be transferred via the swaged weld on the inner pipe than would be transferred for bonded configurations. 

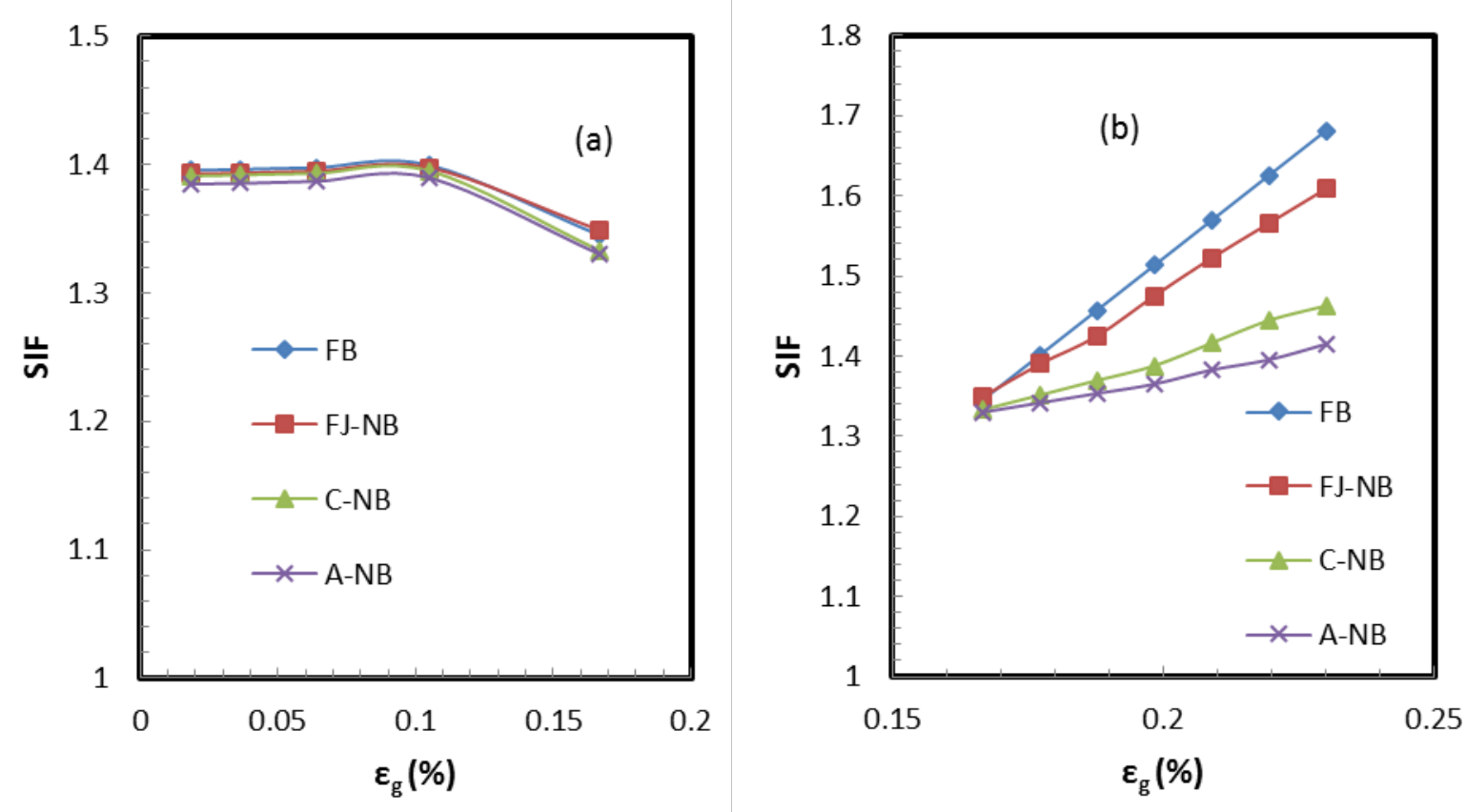

Figure 15. Effect of intra-layer adhesion on SIF for: (a) Zones I (b) Zones II
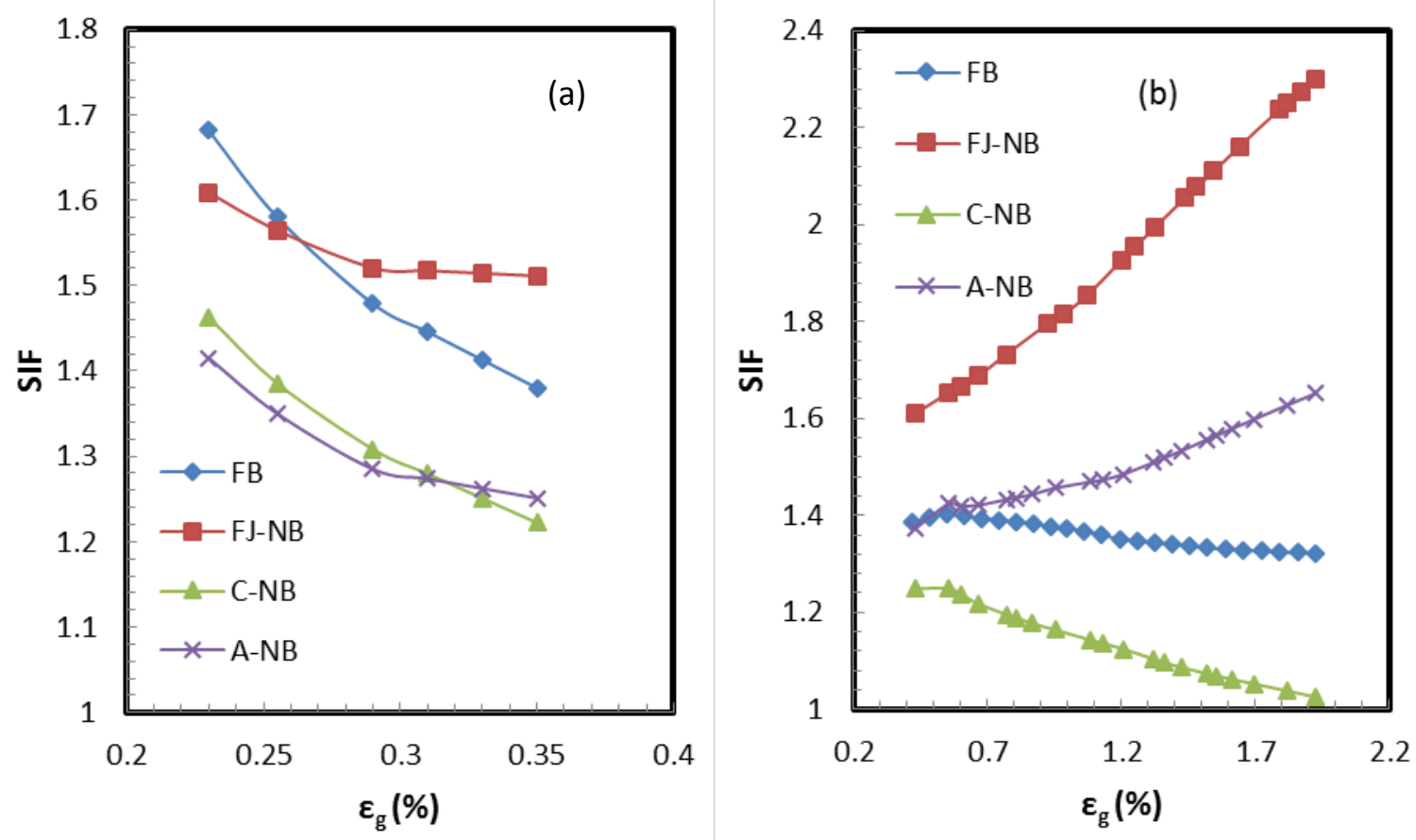

Figure 16. Effect of intra-layer adhesion on SIF for: (a) Zones III (b) Zones IV, V, VI 


\section{Concluding Remarks}

The variation of strain concentration around the field joint for the swaged joint connection for sandwich pipes has been investigated in this study to observe its response under pure bending for reeling installation curvatures. The plastic deformation under pure bending was incorporated in the study as well. Due to lack of experimental work for this unique joint type, two comparative models plastic bending of single X65 pipe (Liessem et al., 2007) and reeling of pipe-in-pipe swaged joint (Jones et al., 2013) - were used to verify the integrity of the FE framework proposed for this study. The FE models investigated the influence of both geometrical and mechanical parameters on the strain intensity occurring adjacent the swaged weld and girth weld sections of the inner pipe. Analysis results revealed that matching the field joint filler properties to that of the core material could significantly reduce the SIF around the swaged weld especially during post yield bending. It is therefore advisable to use a field joint insulation material that closely matches (especially bending stiffness) that of the core material. Increasing the cut-back length would yield significant advantages by reducing the SIF but is not always favourable (a long cut-back length) as that leads to increased offshore time in making a tight connection. Utilising shorter cut-back lengths $r_{i} / L_{f}>0.5$ avails lower SIF to the swaged weld region but greatly increase the SIF at the girth weld region for high reel curvatures. From the sensitivity studies, $r_{i} / L_{f}=0.3-0.4$ would be suitable as they produce a good balance between the SIF at the swaged region and girth region. The choice of weld material and welding procedure will definitely have an impact on the SIF, and as such results showed that utilising a weld metal with a greater yield strength than that of the adjacent pipe would increase the SIF at the swaged weld region but this is only of significance for bending strains below the yield point of the swaged weld. Further research into the effect of the geometry of the swaged weld on the SIF is recommended, looking into dynamic loading (as with the reel installation procedure).

The residual stresses arising as a result of cold working, welding or heat treatment will have an effect on the SIF. Since this study deals with monotonic loading (no stress/strain accumulation criteria defined), the effect of residual stresses will follow a close to linear trend as it will have to be captured by a predefined state before loading in ABAQUS. Future works will incorporate the effect of thermal strains in studying the fracture toughness of the swaged weld in a fully assembled sandwich pipe joint.

The field joint design is critical to building industry confidence in utilising new structural materials in the core of conventional pipe-in-pipe systems. New methods for correction of load condition factors such as in standards like DNV-OS-F101 will need to be considered to satisfactorily take into consideration the geometrical and structural discontinuities. 


\section{Acknowledgements}

Financial support of this research by the University of Aberdeen Elphinstone PhD studentship is gratefully acknowledged. 


\section{References}

Abaqus User's and Theory Manuals. 2014; Version 6.14

An, C., Duan, M., Toledo Filho, R. D., Estefen, S. F., 2014. Collapse of sandwich pipes with PVA fiber reinforced cementitious composites core under external pressure. Ocean Engineering 82, 1-13.

Arjomandi, K., Taheri, F., 2010. Elastic buckling capacity of bonded and unbonded sandwich pipes under external hydrostatic pressure. Journal of Mechanics of Materials and Structures 5(3), 391-408.

Arjomandi, K., Taheri, F., 2011a. Stability and post-buckling response of sandwich pipes under hydrostatic pressure. International Journal of Pressure Vessels and Piping 88 (4), 138-148.

Arjomandi, K., Taheri, F., 2011b. A new look at the external pressure capacity of sandwich pipes. Marine Structures 24 (1), 23-42.

Arjomandi, K., Taheri, F., 2011c. The influence of intra-layer adhesion configuration of the pressure capacity and optimized configuration of sandwich pipes. Ocean Engineering 38 (17-18), 1869-1882.

Arjomandi, K., Taheri, F., 2012. Bending capacity of sandwich pipes. Ocean Engineering 48 (1), 17-31.

Bai, Q., Bai, Y., 2014. Subsea Pipeline Design, Analysis, and Installation. Elsevier, Amsterdam.

Boi, J., Lynch, B. and Sloan, C., 2012. Development and Application of Reelable PiP Bulkhead Technology. Offshore Technology Conference. OTC 23112.

Bruschi, R., Vitali, L., Marchionni, L., Parrella, A., Mancini, A., 2015. Pipe technology and installation equipment for frontier deep water projects. Ocean Engineering 108, 369-392.

Castello, X., Estefen, S.F., 2007. Limit strength and reeling effects of sandwich pipes with bonded layers. International Journal of Mechanical Science 49(5), 577-588.

Castello, X., Estefen, S.F., 2008. Sandwich Pipes for Ultra Deepwater Applications. Offshore Technology Conference, 5-8 May 2008, Houston TX, USA. OTC 19704

Chen, Y.-F., Zhang, J., Zhang, H., Li, X., Zhou, J., Cao, J., 2016. Ultimate bending capacity of strain hardening steel pipes. China Ocean Engineering 30(2), 231-241. 
Crome, T., 1999. Reeling of Pipelines with Thick Insulation Coating, Finite-Element Analysis of Local Buckling. Offshore Technology Conference 3-5 May 199, Houston TX, USA. OTC 10715.

DNV Offshore Standard. DNV-OS-F101, Submarine Pipeline Systems. GCS AS, Norway. Det Norske Veritas, 2013

Dixon, M., Jackson, D., El Chayeb, A., 2003 Deepwater Installation Techniques for Pipe-in-Pipe Systems Incorporating Plastic Strains. Offshore Technology Conference, 5-8 May 2003, Houston TX, USA. OTC 15373.

Estefen, S.F., Netto, T.A., Pasqualino, I.P., 2005. Strength Analyses of Sandwich Pipes for Ultra Deepwaters. ASME Journal of Applied Mechanics 72(7), 599-608.

Janton, S., 2006. North Sea Forvie field overcomes challenges of long-distance pipe-in-pipe. Offshore 66 (5), 108-109.

Hausner, M., Dixon, M., 2002. Optimized design of pipe-in-pipe systems. Offshore Technology Conference, 6-9 May 2002, Houston TX, USA. OTC 14182.

Hausner, M., Dixon, M., 2004. Optimized design of pipe-in-pipe systems. Society of Petroleum Engineers. SPE 87632.

He, T., Duan, M., Wang, J., Lv, S., An, C., 2015. On the external pressure capacity of deepwater sandwich pipes with inter-layer adhesion conditions. Applied Ocean Research 52(8), 115-124.

Hooper, J., Maschner, E., Farrant, T, 2004. HT/HP Pipe-in-Pipe Snaked Lay Technology - Industry Challenges. Offshore Technology Conference, 3-6 May 2004, Houston TX, USA. OTC 16379.

Jones, R. L., Geertsen, C., Booth, P., Mair, J. A., Sriskandarajah, T. and Rao, V., 2013. Pipe-in-Pipe Swaged Field Joint for Reel Lay. Offshore Technology Conference. OTC 24077.

Kyriakides, S., Corona, E., 2007. Mechanics of offshore pipelines: Volume 1. Elsevier, Amsterdam.

Liessem, A., Knauf, G., Zimmermann, S., 2007. Strain Based Design: What the Contribution of a Pipe Manufacturer Can Be. International Society of Offshore and Polar Engineers. ISOPE-2007-SBD14.

Mallik, A., Atin, C., Wang, J., Deleye, X., Legras, J.-L., 2013. Control of the Integrity of Swaged Weld on Insulated Pipe-in-Pipe. Offshore Technology Conference, 6-9 May 2013, Houston TX, USA. OTC 23973. 
Nourpanah, N., Taheri, F., 2012. A comprehensive parametric finite element study on the development of strain concentration in concrete coated offshore pipelines. Transactions of ASME Journal of pressure Vessel Technology 134(6), 061701-1 - 061701-10.

Paz, C.M., Fu, G., Estefen, S.F., Loureno, M.I., Chujutalli, J.A.H., 2015. Sandwich Pipe: Reel-Lay Installation Effects. Proceedings of the ASME 2015 34th International Conference on Ocean, Offshore and Arctic Engineering, 31 May - 5 June 2015, St. John's, Newfoundland, Canada. OMAE2015-41089.

Roberts, C., Rathbone, A., Timmins, D., Cumming, G., Tørnes, K., 2009. Strain intensification due to material discontinuity at field joints adjacent to thick wall insulation coating. Proceedings of the ASME $28^{\text {th }}$ International Conference on Ocean, Offshore and Arctic Engineering, 31 May - 5 June 2009, Honolulu HI, USA. OMAE2009-79779.

Sriskandarajah, T., Howard-Jones, A.L., Bedrossian, A.N., 2003. Extending the strain limits for reeling small diameter flowlines. Proceedings of the $13^{\text {th }}$ International Offshore and Polar Engineering Conference, 25-30 May 2003, Honolulu HI, USA.

Sriskandarajah, T., Ragupathy, P., Rao, V., 2016. Design aspects of pipe-in-pipe systems for HP-HT applications. Offshore Technology Conference, 2-5 May 2016, Houston TX, USA. OTC 27046.

Thielhelm, H.W., 1968. Pipe Coupling Techniques for Marine Pipelines. 1968. SPE: Society of Petroleum Engineers.

Zandberg, A.S., Ladyzhanskii, A.P., 2005. Evaluation of welding stresses in the root weld of circular joints in transmission pipelines. Welding International 19(4), 309-311. 